\title{
Evaluation of antioxidant potential and antimicrobial studies of bark of medicinal plant, Mallotus tetracoccus (Roxb.) Kurz.
}

\author{
Ramalakshmi S. and Muthuchelian K.* \\ Department of Bioenergy, School of Energy, Environment and Natural Resources, Madurai Kamaraj University, \\ Madurai-625 021, India. \\ Accepted 9 May, 2012
}

\begin{abstract}
The present study was aimed to investigate the total phenols, flavonoids, carotenoids, antioxidant activity and antimicrobial activity of the bark extract of Mallotus tetracoccus (Roxb.) Kurz. Total phenols, flavonoids and carotenoids in the extract were found to be $55.35 \pm 0.13 \mathrm{mg} \mathrm{GAE}, 260.3053 \pm$ $1.413 \mathrm{mg} \mathrm{QE}$ and $0.182 \pm 0.005 \mathrm{mg} / \mathrm{g}$, respectively. The reducing power and metal chelating activity of the bark extract was said to be increasing with increasing concentration. The metal chelating activity $\left(\mathrm{IC}_{50}\right)$ of the $M$. tetracoccus bark extract was found to be $647.4 \pm 0.321 \mu \mathrm{g} / \mathrm{ml}$, which was higher compared to the standard, ethylenediaminetetraacetic acid (EDTA; $1.89 \pm 0.03 \mu \mathrm{g} / \mathrm{ml}$ ). Antioxidant activity was determined by 2,2-diphenyl-1-picrylhydrazyl (DPPH), ferric thiocyanate (FTC) and thiobarbituric acid (TBA) methods. The antioxidant activity $\left(\mathrm{IC}_{50}\right)$ of the bark extract was said to be 0.504 $\pm 0.002 \mu \mathrm{g} / \mathrm{ml}$ by (DPPH) method. The total antioxidant activity of $M$. tetracoccus ethanolic bark extract was found to be $275.21 \pm 0.21 \mathrm{mg}$ equivalent of ascorbic acid $/ 100 \mathrm{~g}$ of plant extract as determined by phosphomolybdenum method. The antibacterial studies of the ethanolic bark extract was also tested at different concentration of extracts, where $250 \mathrm{mg} / \mathrm{ml}$ concentration of extract showed good inhibitory activity against all the clinically important disease pathogens compared with standard antibiotics like streptomycin and penicillin. The highest inhibition was noted in order of Klebsiella pneumonia (25.33 \pm $0.37 \mathrm{~mm})$, Staphylococcus aureus $(22.83 \pm 0.31 \mathrm{~mm})$, Vibrio cholerae $(20.00 \pm 0.31 \mathrm{~mm})$ and Escherichia coli $(20.22 \pm 0.26 \mathrm{~mm})$. Thus, the bark extract of $M$. tetracoccus was said to possess significant antioxidant and antimicrobial activity, which suggests its use in traditional medicine.
\end{abstract}

Key words: Mallotus tetracoccus, antioxidant, 2,2-diphenyl-1-picrylhydrazyl (DPPH), reducing power, phenols, phosphomolybdenum activity, ferric thiocyanate (FTC), thiobarbituric acid (TBA), biological activity.

\section{INTRODUCTION}

Medicinal plants are still used as radical scavengers to fight against many important diseases, such as cancer. The active phytochemical compounds present in the plants such as carotenoids, terpenoids, flavonoids, polyphenols, alkaloids, tannins and saponins, possess various activities which help in scavenging the free radicals produced during initiation or progression of diseases (Cragg and Newman, 2000). Mallotus tetracoccus (Roxb.) Kurz, found in Western Ghats of

*Corresponding author. E-mail: drchelian1960@yahoo.co.in. Tel: +91 4522458020 .
India, is one of the medicinally important plants belonging to the family Euphorbiaceae. It is commonly known as "vatta kanni" in Tamil. M. tetracoccus (Roxb.) Kurz, are found in evergreen forests up to $1600 \mathrm{~m}$. The common names include Thavatta, Vatta, Vatta kumbil, Vetta kumbil (malayalam) and Uppale mara (kannada). The trees grow up to $5-15 \mathrm{~m}$ tall, leaf blades are triangularovate or ovate, sometimes 1 - or 2-lobate, 10 to $25 \times 9$ to $20 \mathrm{~cm}$, leathery, abaxially brownish tomentose, adaxially glabrous, base obtuse or truncate (biotik.org).

Several species of the genus Mallotus are a rich source of biologically active compounds such as phloroglucinols, tannins, terpenoids, coumarins, benzopyrans and chalcones (Amakura and Toshida, 1996; Tanaka et al., 
1998; Huang et al., 1999; Cheng and Chen, 1999; Wei et al., 2004; $\mathrm{Ma}$ et al., 2004; Likhitwitayawuid and Supudompol, 2005). The reported bioactivities of the extracts or the individual chemical constituents isolated from this genus include antipyretic (Chattopadhyay et al., 2002), anti-inflammatory, hepatoprotective (Kim et al., 2000), antioxidant and radical scavenging activities (Arfan et al., 2007). The active compounds present in the M. tetracoccus ethanolic leaf extract was studied by Ramalakshmi and Muthuchelian (2011). The gas chromatography-mass spectroscopy (GC-MS) analysis showed the presence of various chemical constituents such as bis(2-ethyl hexyl) phthalate (46.78\%), 3-methyl2-(2-oxypropyl) furan (13.31\%), E-8-methyl-9-tetradecen1-ol acetate (6.63\%), octadecanoic acid, 2-oxo (4.46\%) and longiborneol (2.39\%). Thus, the leaf extract of $M$. tetracoccus have been classified as compounds of nature such as diesters $(50 \%)$, alcohols $(15 \%)$, alkanes $(3 \%)$, sesquiterpenes $(5 \%)$, terpenoids $(13 \%)$, fatty acid $(5 \%)$ and sugars $(2.6 \%)$ (RamaLakshmi and Muthuchelian, 2011).

Although researches have reported on $M$. tetracoccus (Roxb.) Kurz. leaves, a literature search revealed no references to investigation on its bark. Thus, the objective of the study was to study the antioxidant and antimicrobial property of $M$. tetracoccus bark extract.

\section{MATERIALS AND METHODS}

\section{Collection of plant material}

The fresh bark of $M$. tetracoccus (Roxb.) Kurz. were collected from the Agasthiar Malai Reserved Forest, Western Ghats, South India and authenticated by the Director, Centre for Biodiversity and Forest Studies, Madurai Kamaraj University. The voucher specimens were deposited in the herbarium of Centre for Biodiversity and Forest Studies of our university (No.AM-07).

\section{Chemicals}

Folin-ciocalteu reagent, sodium carbonate, gallic acid, quercetin, aluminium chloride, potassium ferricyanide, potassium acetate, linoleic acid, ammonium thiocyanate, ferrous chloride, beta hydroxyl toluene, $\alpha$-tocopherol, trichloroacetic acid, 2-thiobarbituric acid, 2,2diphenyl-1-picryl-hydrazyl (DPPH), hydrogen peroxide, diethyl ether, potassium hydroxide, trichloroacetic acid, ferric chloride, ferrozine, ethylenediaminetetraacetic acid (EDTA), ammonium molybdate, ascorbic acid, sodium phosphate and Muller Hinton agar were obtained from Himedia, Merck, Sigma. All other reagents used were of analytical grade.

\section{Preparation of extract}

Fresh barks were shade dried, powdered and extracted with ethanol for 6 to $8 \mathrm{~h}$ using soxhlet apparatus, at a temperature of $80^{\circ} \mathrm{C}$. The extract was then filtered through muslin, evaporated under reduced pressure and vacuum dried to get the viscous residue. The ethanolic extract of the bark was used for antioxidants and antimicrobial studies.

\section{Determination of total phenols and flavonoids}

The total phenolic content was determined according to the method described by Siddhuraju and Becker (2003). Aliquots of each extracts were taken in test tubes and made up to the volume of $1 \mathrm{ml}$ with distilled water. Then $0.5 \mathrm{ml}$ of Folin-ciocalteu phenol reagent (1:1 with water) and $2.5 \mathrm{ml}$ of sodium carbonate solution $(20 \%)$ were added sequentially in each tube. Soon after vortexing the reaction mixture, the test tubes were placed in dark for 40 min and the absorbance was recorded at $725 \mathrm{~nm}$ against the reagent blank. Total phenol contents were expressed in terms of gallic acid equivalent ( $\mathrm{mg} / \mathrm{g}$ of dry mass), which is used as a reference compound.

Flavonoid content was determined according to the aluminium chloride colorimetric method by Chang et al. (2002) with some modifications. Quercetin was used as a standard to make the calibration curve. The sample solution $(0.5 \mathrm{ml})$ was mixed with 1.5 $\mathrm{ml}$ of $95 \%$ ethanol, $0.1 \mathrm{ml}$ of $10 \%$ aluminium chloride hexahydrate, $0.1 \mathrm{ml}$ of $1 \mathrm{M}$ potassium acetate and $2.8 \mathrm{ml}$ of distilled water. After incubation at room temperature for $40 \mathrm{~min}$, the absorbance of the reaction mixture was measured at $415 \mathrm{~nm}$. The same amount $(0.1$ $\mathrm{ml}$ ) of distilled water substituted for the amount of $10 \%$ aluminium chloride as the blank and a seven point standard curve (0 to 500 $\mu \mathrm{g} / \mathrm{ml}$ ) was obtained.

\section{Determination of carotenoids}

Total carotenoids were determined by the method of Jensen (1978). One gram sample was extracted with $100 \mathrm{ml}$ of $80 \%$ methanol solution and centrifuged at $4000 \mathrm{rpm}$ for $30 \mathrm{~min}$. The supernatant was concentrated to dryness. The residue was dissolved in $15 \mathrm{ml}$ of diethyl ether and after addition of $15 \mathrm{ml}$ of $10 \%$ methanolic $\mathrm{KOH}$, the mixture was washed with $5 \%$ ice-cold saline water to remove alkali. The free ether extract was dried over anhydrous sodium sulphate for $2 \mathrm{~h}$. The ether extracts were filtered and its absorbance was measured at $450 \mathrm{~nm}$ using ether as blank.

\section{Antioxidant assay}

The antioxidant activity of the plant extracts was tested using two methods: ferric thiocyanate (FTC) and thiobarbituric acid (TBA) methods.

\section{Ferric thiocyanate (FTC) method}

The standard method described by Kikuzaki and Nakatani (1993) was used. A mixture of $4.0 \mathrm{mg}$ plant extract in $4 \mathrm{ml}$ absolute ethanol, $4.1 \mathrm{ml}$ of $2.5 \%$ linolenic acid in absolute ethanol, $8.0 \mathrm{ml}$ of $0.05 \mathrm{M}$ phosphate buffer $(\mathrm{pH} 7.0)$ and $3.9 \mathrm{ml}$ of water was placed in a vial with a screw cap and then placed in an oven at $40^{\circ} \mathrm{C}$ in the dark. To $0.1 \mathrm{ml}$ of this solution was added $9.7 \mathrm{ml}$ of $75 \%$ ethanol and $0.1 \mathrm{ml}$ of $30 \%$ ammonium thiocyanate. Precisely $3 \mathrm{~min}$ after addition of $0.1 \mathrm{ml}$ of $0.02 \mathrm{M}$ ferrous chloride in $3.5 \% \mathrm{HCl}$ to the reaction mixture, the absorbance of red colour was measured at $500 \mathrm{~nm}$ each $24 \mathrm{~h}$ until the day after absorbance of control reached maximum. Beta hydroxyl toluene (BHT) and $\alpha$ - tocopherol were used as positive controls, while the mixture without plant sample was used as the negative control.

\section{Thiobarbituric acid (TBA) method}

The method of Ottolenghi (1959) was referred. Briefly, Two $\mathrm{ml}$ of $20 \%$ trichloroacetic acid and $2 \mathrm{ml}$ of $0.67 \% 2$-thiobarbituric acid was added to $1 \mathrm{ml}$ of sample solution, as prepared in FTC method. The 
Table 1. Total phenols, flavonoids and carotenoids contents of Mallotus tetracoccus bark extract.

\begin{tabular}{ll}
\hline Determination of Phyto-constituent & Mallotus tetracoccus bark extract \\
\hline Total phenols & $55.35 \pm 0.13 \mathrm{mg} \mathrm{GAE}$ \\
Flavonoids & $260.3053 \pm 1.413 \mathrm{mg} \mathrm{QE}$ \\
Carotenoids & $0.182 \pm 0.005 \mathrm{mg} / \mathrm{g}$ \\
\hline
\end{tabular}

mixture was placed in a boiling water bath and after cooling was centrifuged at $3000 \mathrm{rpm}$ for $20 \mathrm{~min}$. Absorbance of supernatant was measured at $552 \mathrm{~nm}$. Antioxidant activity was based on the absorbance on the final day of FTC method.

\section{DPPH free radical scavenging activity}

The free radical scavenging activity of the extracts, based on the scavenging activity of the stable 2,2-diphenyl-2-picrylhydrazyl (DPPH) free radical was determined by the method described by Braca et al. (2002). Plant extract $(0.1 \mathrm{ml})$ was added to $3 \mathrm{ml}$ of a $0.004 \%$ methanol solution of DPPH. Absorbance at $517 \mathrm{~nm}$ was determined after $30 \mathrm{~min}$, and the percentage inhibition activity was calculated as $\left[\left(A_{0}-A_{1}\right) / A_{0}\right] \times 100$, Where $A_{0}$ is the absorbance of the control and $A_{1}$ is the absorbance of the extract/ standard. A blank is the absorbance of the control reaction (containing all reagents except the test compound). A percent inhibition versus concentration curve was plotted and the concentration of sample required for $50 \%$ inhibition was determined and represented as $I_{50}$ value for each of the test solutions.

\section{Reducing power assay}

Aliquots of each extracts were taken in test tubes and dissolved in 1 $\mathrm{ml}$ of $0.2 \mathrm{M}$ phosphate buffer in a test tube to which was added $5 \mathrm{ml}$ of $0.1 \%$ solution of potassium ferric cyanide (Siddhuraju et al., 2002). The mixture was incubated $50^{\circ} \mathrm{C}$ for $20 \mathrm{~min}$. Subsequently, 5 $\mathrm{ml}$ of trichloroacetic acid (10\%) (w/v) solution was added and the mixture was then centrifuged at $7000 \mathrm{rpm}$ for $10 \mathrm{~min}$. A $5 \mathrm{ml}$ of aliquot of the upper layer was combined with $5 \mathrm{ml}$ of distilled water and $1 \mathrm{ml}$ of ferric chloride solution $(0.1 \%)$ and absorbance was recorded at $700 \mathrm{~nm}$ against reagent blank. A higher absorbance of the reaction mixture indicates greater reducing power of the sample.

\section{Metal chelating activity}

The chelating of ferrous ions by $M$. tetracoccus (Roxb) Kurz. ethanolic bark extract was estimated by the method of Dinis et al. (1994). Briefly, the extract samples $(250 \mu \mathrm{L})$ were added to a solution of $2 \mathrm{mmol} / \mathrm{L} \mathrm{FeCl}_{2}(0.05 \mathrm{ml})$. The reaction was initiated by the addition of $5 \mathrm{mmol} / \mathrm{L}$ ferrozine $(0.2 \mathrm{ml})$ and the mixture was shaken vigorously and left standing at room temperature for $10 \mathrm{~min}$, after which the absorbance was measured spectrophotometrically at $562 \mathrm{~nm}$. The chelating activity of the extracts was evaluated using EDTA as standard. The metal chelating activity of the extract is expressed as mg EDTA equivalent/g extract.

\section{Phosphomolybdenum activity}

The antioxidant activity of samples was evaluated by the green phosphomolybdenum complex formation according to the method of Prieto et al., 1999. An aliquot of $100 \mu \mathrm{l}$ of sample solution was combined with $1 \mathrm{ml}$ of reagent solution (0.6 M sulphuric acid, 28 $\mathrm{mM}$ sodium phosphate and $4 \mathrm{mM}$ ammonium molybdate) in a $4 \mathrm{ml}$ vial. The vials were canned and incubated in a water bath at $95^{\circ} \mathrm{C}$ for $90 \mathrm{~min}$. After the samples have cooled to room temperature, the absorbance of the mixture was measured at $695 \mathrm{~nm}$ against a blank.

The results were reported (ascorbic acid equivalent antioxidant activity) as mean values expressed in $\mathrm{g}$ of ascorbic acid equivalents $/ 100 \mathrm{~g}$ extract.

\section{Test organisms}

The ethanolic bark extract of $M$. tetracoccus (Roxb.) Kurz. was screened against four bacterial pathogens. The clinical isolates used for study are Staphylococcus aureus, Escherichia coli, Klebsiella pneumonia and Vibrio cholerae.

\section{Antibacterial Screening}

The different concentrations of the bark extracts $(50,100$ and 250 $\mathrm{mg} / \mathrm{L}$ ) were tested for antibacterial activity using agar disc diffusion assay according to the method of Bauer et al. (1966). The strains of microorganisms obtained were inoculated in conical flask containing $100 \mathrm{ml}$ of nutrient broth. These conical flasks were incubated at $37^{\circ} \mathrm{C}$ for $24 \mathrm{~h}$ and were referred to as seeded broth. Media were prepared using Muller Hinton Agar (Himedia, Mumbai, India), poured on Petri dishes and inoculated with the test organisms from the seeded broth using cotton swabs. Sterile discs of $6 \mathrm{ml}$ width had been impregnated with $20 \mu \mathrm{L}$ of test extract and introduced onto the upper layer of the seeded agar plate. The plates were incubated overnight at $37^{\circ} \mathrm{C}$. Antibacterial activity was assigned by measuring the inhibition zone formed around the discs. The experiment was done three times and the mean values were presented. Streptomycin $(10 \mu \mathrm{g} / \mathrm{disc})$ and penicillin $(10 \mu \mathrm{g} / \mathrm{disc})$ were used as standards.

\section{RESULTS}

\section{Determination of total phenols and flavonoids}

The percentage yields of the ethanolic bark extract of $M$. tetracoccus (Roxb.) Kurz. were found to be $14.89 \%$. Total phenolic content of the ethanolic extract of $M$. tetracoccus (Roxb.) Kurz. bark extract was $55.35 \pm 0.13 \mathrm{mg}$ gallic acid equivalent per gram of plant extract (Table 1). The flavonoid contents of the $M$. tetracoccus ethanolic bark extract was $260.305 \pm 1.413 \mathrm{mg}$ Quercetin equivalent per gram of plant extract (Table 1).

While the carotenoids contents of the $M$. tetracoccus ethanolic bark extract were found to be $0.182 \pm 0.005$ $\mathrm{mg} / \mathrm{g}$ (Table 1). 


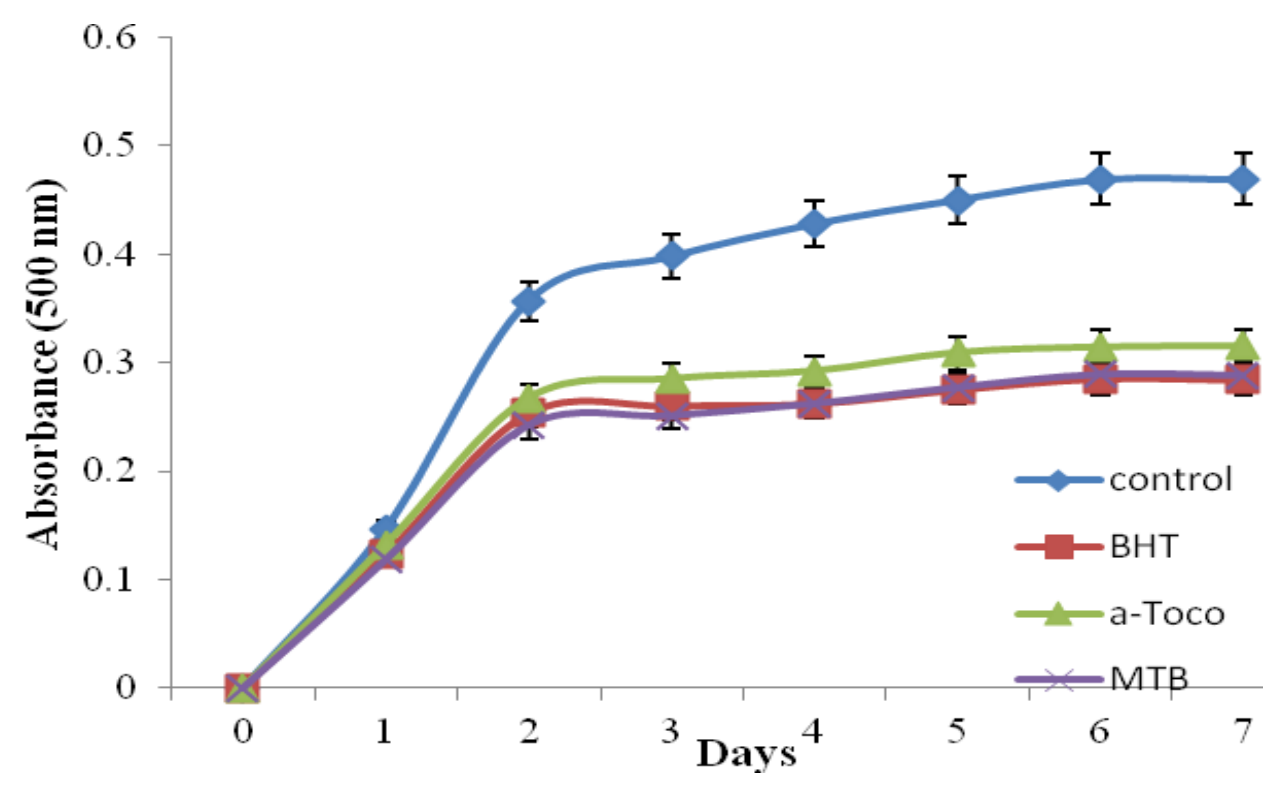

Figure 1. Antioxidant activity of the standards ( $\alpha$-tocopherol and beta hydroxy toluene) and Mallotus tetracoccus bark extract as measured by FTC method. Each experiment was executed in triplicate and repeated three times.

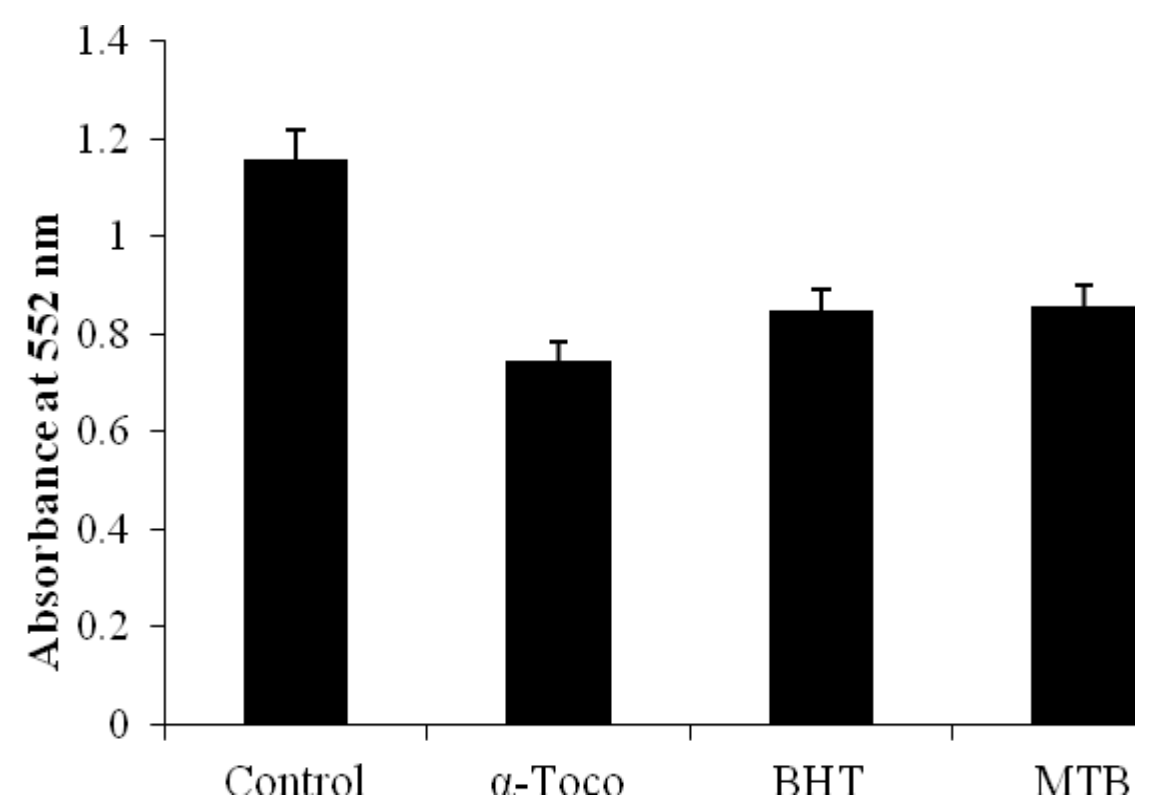

Figure 2. Total antioxidant activity of samples by TBA method.

\section{Antioxidant assay}

\section{Ferric thiocyanate (FTC) method}

As shown in Figure 1, the absorbance of the $M$. tetracoccus bark extract and beta hydroxyl toluene $(\mathrm{BHT})$ at day 6 and 7 was significantly $(P<0.05)$ decreased when compared with the absorbance of standard ( $\alpha$ - tocopherol) at day 6 and 7 . The control had the highest value throughout the study.

\section{Thiobarbituric acid (TBA) method}

Figure 2 shows the absorbance of standards and bark extract. The absorbance values of bark extract and 


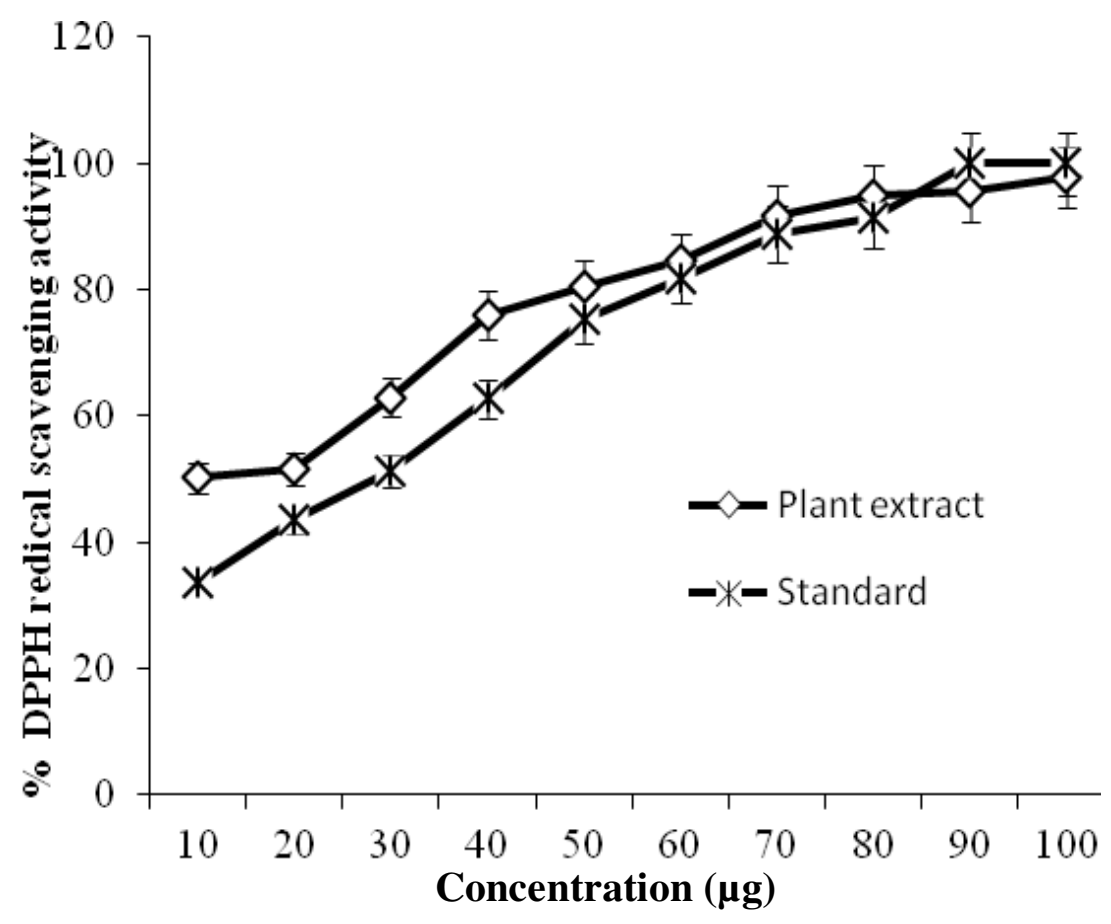

Figure 3. DPPH radical scavenging activity of Mallotus tetracoccus (Roxb.) Kurz. ethanolic bark extract.

standard BHT, where significantly higher than the $\alpha$ tocopherol.

\section{DPPH free radical scavenging activity}

The radical scavenging activity of the $M$. tetracoccus ethanolic bark extract was tested using stable free radical DPPH (deep purple colour), as DPPH has the advantage of being unaffected by certain side reactions. Figure 3 shows the DPPH radical scavenging activity of $M$. tetracoccus with ascorbic acid as reference, where the $\mathrm{IC}_{50}$ values for the $M$. tetracoccus ethanolic bark extract $(0.504 \pm 0.002 \mu \mathrm{g} / \mathrm{ml})$ which was said to be significant than the standard ascorbic acid $\left(\mathrm{IC}_{50}=30.31 \pm 0.01\right.$ $\mu \mathrm{g} / \mathrm{ml})$.

\section{Reducing power assay}

Figure 4 shows the reducing power of the $M$. tetracoccus ethanolic bark extract using potassium ferricyanide reduction method. The absorbance value of the extract shows higher increase with increase in concentration, when compared to standard ascorbic acid.

\section{Metal chelating activity}

Figure 5 shows the metal chelating activity of the $M$. tetracoccus bark extract, where $\mathrm{IC}_{50}$ of plant extract was said to be $647.4 \pm 0.321 \mu \mathrm{g} / \mathrm{ml}$, which was higher compared to the standard, EDTA $(1.89 \pm 0.03 \mu \mathrm{g} / \mathrm{ml})$.

\section{Phosphomolybdenum activity}

The total antioxidant activity of $M$. tetracoccus (Roxb.) Kurz. ethanolic bark extract was found to be $275.21 \pm$ $0.21 \mathrm{mg}$ equivalent of ascorbic acid $/ 100 \mathrm{~g}$ of plant extract as determined by phosphomolybdenum method.

\section{Antibacterial screening}

The M. tetracoccus (Roxb.) Kurz. ethanolic bark extract showed good inhibition against both Gram positive and Gram negative organisms at higher concentration of 250 $\mathrm{mg} / \mathrm{L}$ (Table 2). The highest inhibition was noted in order of $K$. pneumonia $(25.33 \pm 0.37 \mathrm{~mm})$, S. aureus $(22.83 \pm$ $0.31 \mathrm{~mm}), V$. cholerae $(20.00 \pm 0.31 \mathrm{~mm})$ and $E$. coli $(20.22 \pm 0.26 \mathrm{~mm})$.

\section{DISCUSSION}

The phenolic compounds present in natural products have higher antioxidant activity than synthetic antioxidants, also by acting as free radical terminators ( $\mathrm{Lu}$ and Foo, 2000). The total phenolic content of the stem 


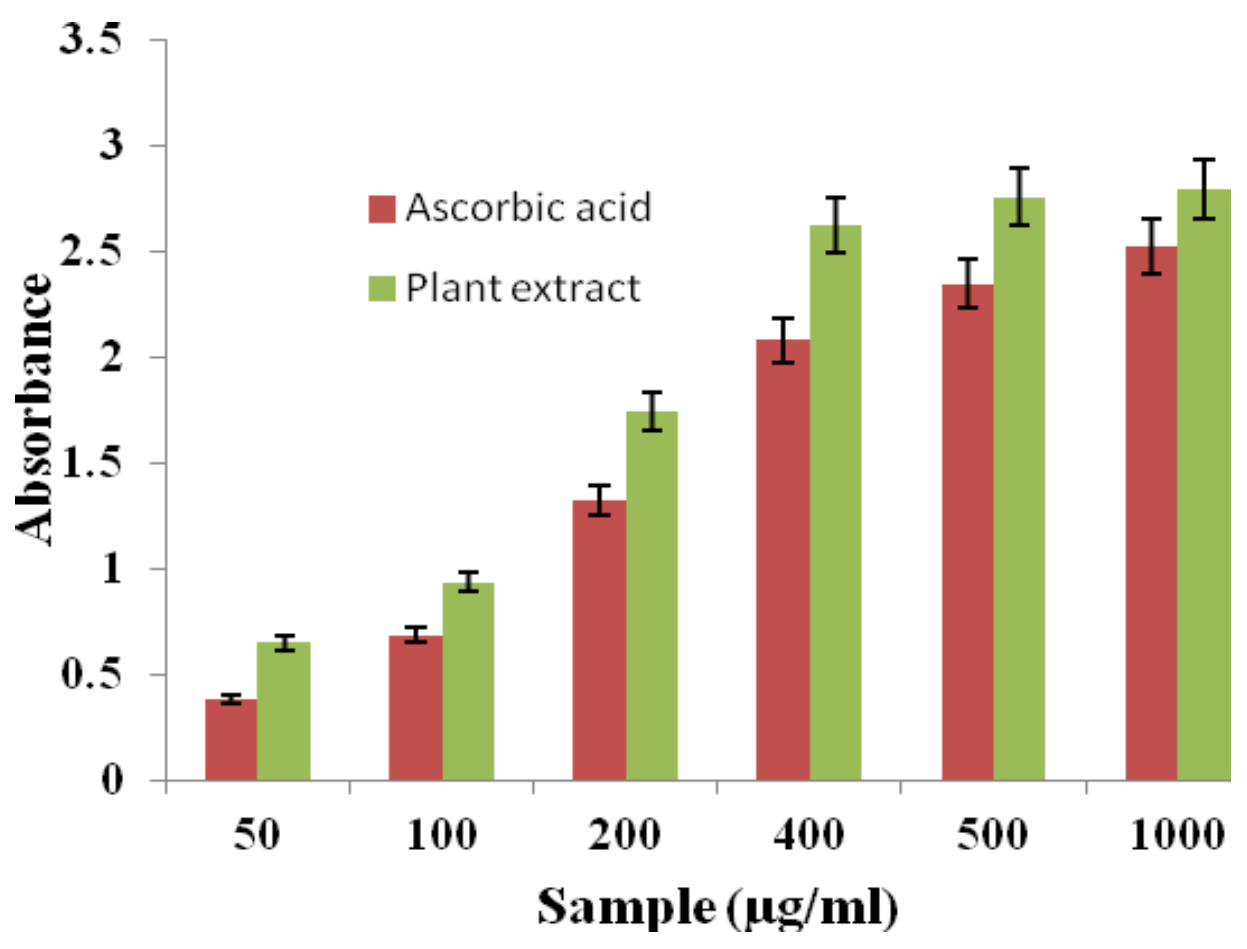

Figure 4. Reducing power of the Mallotus tetracoccus (Roxb.) Kurz. ethanolic bark extract.

bark of Gmelina arborea was $356 \pm 1.4 \mathrm{mg} \mathrm{g}^{-1}$ (Patil et al., 2009). The bark extract of Acacia confusa showed total phenolic content of $470.6 \mathrm{mg} / \mathrm{g}$, where the antioxidant activity by $\mathrm{DPPH}$ possessed $\mathrm{IC}_{50}$ values ranging from 1 to $5 \mu \mathrm{g} / \mathrm{ml}$ (Chang et al., 2001). Chamaecyparis obtusa various fractions of bark extract was also evaluated for antioxidant activity, and the total phenolic content varied from 27.71 to $102.86 \mathrm{mg} \mathrm{GAE} \mathrm{g}^{-1}$ dry weight for fractions (Marimuthu et al., 2008). The flavonoids possess antioxidant activity acting through scavenging or chelating process, thereby having considerable effect on human health and nutrition (Kessler et al., 2003). Since the bark extract of $M$. tetracoccus showed higher amount of phenolic compounds, this suggests their usage as a good source of natural antioxidant, preventing free radical-mediated oxidative damage.

In addition, carotenoids have a positive role on the epithelisation process and influence the cell cycle progression of the fibroblasts (Stiavala et al., 1996). Carotenoids act as photo-protective agents, reducing skin cancer, skin related diseases, photo-allergy and sun burns (Lee et al., 2000). The methanolic and aqueous bark extracts of Mespilus germanica L. exhibit $287.24 \pm$ $14.5,457.07 \pm 22.3 \mathrm{mg} \mathrm{g}^{-1} ; 33.73 \pm 2.1,34.12 \pm 1.9 \mathrm{mgg}^{-}$ ${ }^{1} ; 11.4 \pm 0.8,10.7 \pm 0.6 \mathrm{gml}^{-1} ; 28.4 \%, 504 \pm 34.5\left(\mathrm{IC}_{50}\right)$ for total phenol, total flavonoid, DPPH free radical scavenging and $\mathrm{Fe}^{2+}$ chelating ability, respectively (Nabavi et al., 2011).

\section{Ferric thiocyanate (FTC) method}

The ferric thiocyanate (FTC) results showed that $M$. tetracoccus bark extract had greater antioxidant activity when compared with $\alpha$-tocopherol. The absorbance values for all the samples were maximal on the 6th day and then dropped at the 7th day due to malondialdehyde (MDA) compounds from linoleic acid oxidation, in which peroxide reacts with ferrous chloride to form a reddish ferric chloride pigment. The control had increasing absorbance values from 0 day until the absorbance reached the maximal level at 6 day and the absorbance value dropped at 7 day.

The reaction in the FTC method is due to the MDA compounds from the linoleic acid oxidation in which peroxide reacts with ferrous chloride to form a reddish ferric chloride pigment (Al-Naqeeb et al., 2009). Peroxides are slowly decayed to lower molecular compounds during the oxidation course (Behbahani et al., 2007). The bark and leaf extracts of $M$. germanica L. also exhibited higher antioxidant activity in the ferric thiocyanate (FTC) method showing higher peroxidation inhibition than vitamin $\mathrm{C}$ and BHA at the 96th hour $(\mathrm{p}<0.05)$ (Nabavi et al., 2011).

\section{Thiobarbituric acid (TBA) method}

The TBA results were in agreement with the FTC results. 

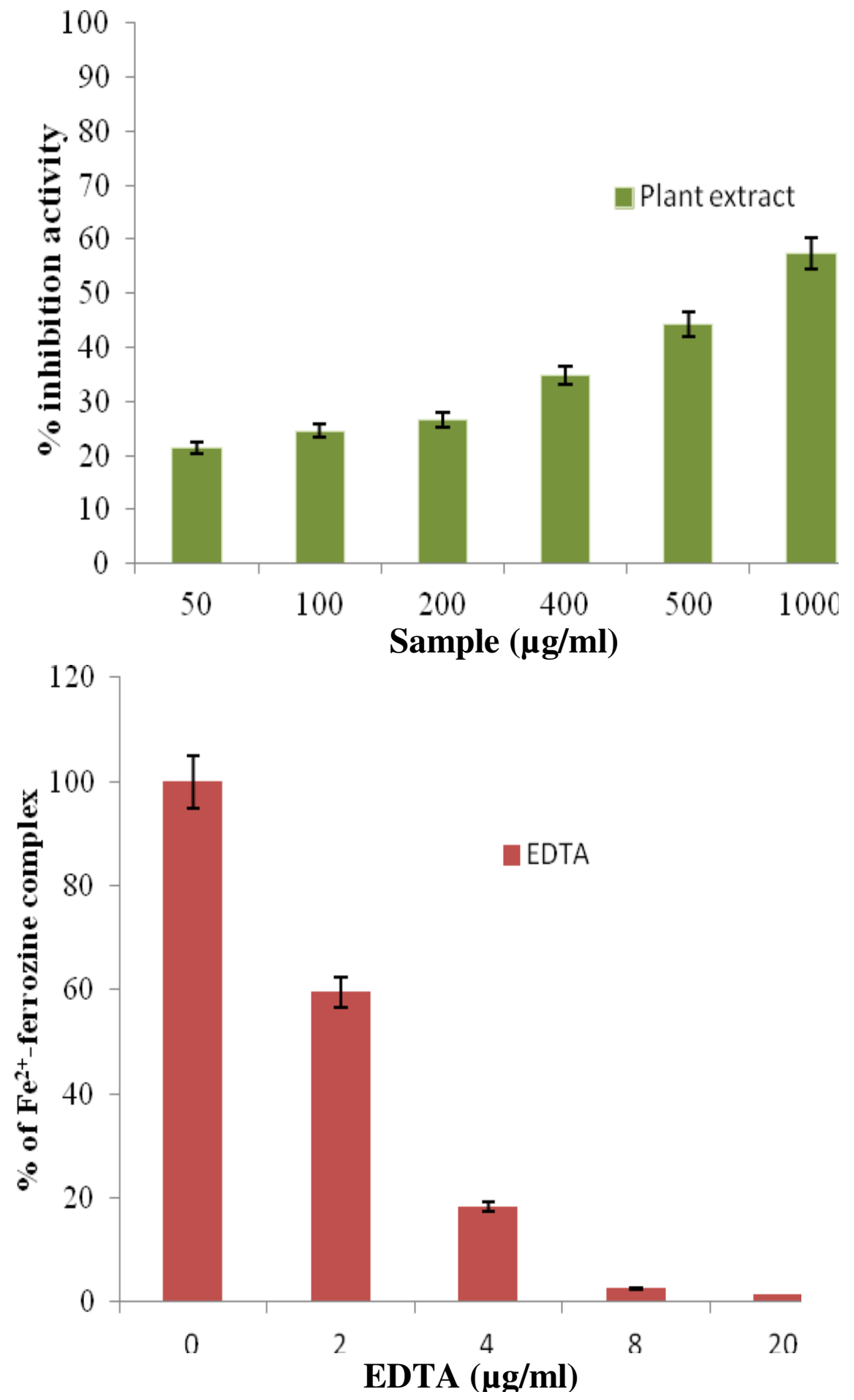

Figure 5. Metal chelating activity of Mallotus tetracoccus (Roxb.) Kurz. ethanolic bark extract.

After sometime, malonaldehyde a secondary product of lipid peroxidation changes into alcohol and acid. The alcohol and acid cannot be detected with a spectrophotometer (Rahmat et al., 2003). The FTC method indicates the amount of peroxide in the initial stages of lipid peroxidation (Saha et al., 2004; Rahmat et al., 2003), whereas the thiobarbituric acid method shows the amount of peroxide in the secondary stage of lipid 
Table 2. Antibacterial activities of ethanolic bark extract of Mallotus tetracoccus.

\begin{tabular}{lccccc}
\hline \multirow{2}{*}{ Microorganisms } & \multicolumn{5}{c}{ Inhibition zone in diameter $\mathbf{( m m}$ ) } \\
\cline { 2 - 6 } & Streptomycin & Penicillin & $\mathbf{5 0} \mathbf{~ m g / L ~ E x t r a c t ~}$ & $\mathbf{1 0 0} \mathbf{~ m g / L ~ E x t r a c t}$ & $\mathbf{2 5 0} \mathbf{~ m g / L ~ E x t r a c t}$ \\
\hline Vibrio cholerae & $16.80 \pm 0.87$ & $19.34 \pm 0.38$ & $8.00 \pm 0.35$ & $19.21 \pm 0.48$ & $20.00 \pm 0.31$ \\
Escherichia coli & $14.70 \pm 0.60$ & $10.10 \pm 0.25$ & $17.00 \pm 0.42$ & $18.65 \pm 0.33$ & $20.22 \pm 0.26$ \\
Klebsiella pneumonia & $12.10 \pm 0.25$ & $17.60 \pm 0.71$ & $17.12 \pm 0.43$ & $20.34 \pm 0.26$ & $25.33 \pm 0.37$ \\
Staphylococcus aureus & $22.80 \pm 0.35$ & $23.10 \pm 0.45$ & $15.15 \pm 0.34$ & $20.55 \pm 0.37$ & $22.83 \pm 0.31$ \\
\hline
\end{tabular}

Values are inhibition zone $(\mathrm{mm})$, and an average of triplicate.

peroxidation (Rahmat et al., 2003). Therefore, the higher antioxidant activity found from the ferric thiocyanate method indicated that the amount of peroxide in the initial stage of lipid peroxidation was greater than the amount of peroxide in the secondary stage (Rezaeizadeh et al., 2011).

\section{DPPH free radical scavenging activity}

The antioxidants present in the extract quenches the DPPH free radicals (by providing hydrogen atom or by electron transfer, conceivably via a free radical attack on the DPPH molecule) and convert them to a colourless product (2, 2-diphenyl-1- picrylhydrazyl, or a substituted analogous hydrazine), resulting in a decreasing absorbance at the $517 \mathrm{~nm}$ (Yamaguchi et al., 2002). The antioxidative effect of the bark extract in these studies may be due to the presence of thiocyanic acid, furfural and 4H-pyran-4-one, 2,3-dihydro-3,5-dihydroxy-6-methyl compounds (unpublished results). In addition, antioxidative activities observed in the extracts could be the synergistic effect of more than two compounds that may be present in the plant. It has been reported that most natural antioxidative compounds often work synergistically with each other to produce a broad spectrum of antioxidative activities that creates an effective defence system against free radical attack (Lu and Foo, 1995).

Stem bark extract of M. germanica L. (aqueous and methanol) showed best activity in 1,1- diphenyl-2-picryl hydrazyl (DPPH) radical scavenging activity with $\mathrm{IC}_{50}=$ $10.7 \pm 0.6$ and $11.4 \pm 0.8 \mathrm{\mu gml}^{-1}$, respectively (Nabavi et al., 2011). The alcoholic extract of stem bark of Terminalia arjuna showed potent antioxidant activity with $E_{50}$ value of $2.491 \pm 0.160$ (Viswanatha et al., 2010). Stem bark of Gmelina arborea studied for antioxidant activity also possessed IC50 values of extract and standard were $46.2 \pm 1.2$ and $28.80 \pm 0.50$, respectively (Patil et al., 2009). Ethyl acetate extract of Tectona grandis bark showed very high activity with 98.6\% inhibition against DPPH and ABTS+ free radicals (Krishna et al., 2010). Moreover, the Ethyl acetate soluble fraction of Chamaecyparis obtusa bark was found to be the best antioxidant-rich fraction in terms of DPPH $(0.15$ to $0.26 \mathrm{mmol} \mathrm{L}^{-1}$ Trolox equivalents) and reducing power assays (Marimuthu et al., 2008).

\section{Reducing power assay}

The yellow colour of test solution changes to various shades of green and blue due to the reduction of $\mathrm{Fe}^{3+} /$ Ferric cyanide complex to ferrous form by the antioxidants present in the extract. Thus, the reducing power of medicinal plants and vegetables are said to be well associated with the antioxidant activity and its phenolic constituents (Siddhuraju and Becker, 2003). The leaves and bark extracts of $M$. germanica $\mathrm{L}$. also showed good reducing power than fruit extract (Nabavi et al., 2011, 2003).

\section{Metal chelating activity}

In this metal chelating activity, the presence of chelating agents in the extract of $M$. tetracoccus disrupts the ferrozine-Fe ${ }^{2+}$ complex formation, thus decreasing the red colour. It is reported that chelating agents are effective as secondary antioxidants as they stabilise the oxidised form of the metal ion by reducing the redox potential (Gardner et al., 2000). Iron can generate free radicals from peroxides and may be implicated in human cardiovascular disease (Halliwell and Gutteridge, 1990). Bivalent transition metal ions play an important role as catalysts of oxidative processes, leading to the formation of hydroxyl radicals and hydroperoxide decomposition reactions via Fenton chemistry (Halliwell, 1997). These processes are delayed by iron chelators, which mobilize tissue iron by forming soluble and stable complexes (Nabavi et al., 2011). Ferrozine can quantitatively form complexes with $\mathrm{Fe}^{2+}$. In the presence of other chelating agents, the ferrozine complex formation is disrupted, resulting in a decrease in the red color of the complexes (Ebrahimzadeh et al., 2008).

\section{Phosphomolybdenum activity}

This method is based on the formation of green phosphomolybdenum complex at $95^{\circ} \mathrm{C}$ measured at an 
intensity of absorbance at $695 \mathrm{~nm}$. In this method, reduction of $\mathrm{Mo}(\mathrm{VI})$ to $\mathrm{Mo}(\mathrm{V})$ by the antioxidant compounds present in the plant extract, forming green phosphate/Mo (V) complex takes place (Sowndhararajan et al., 2010).

\section{Antibacterial screening}

The different fractions of methanolic, ethanolic and aqueous extracts of stem bark of Acacia leucophloea was studied for their antimicrobial activity against different bacterial strains and fungal strains. Methanol extract exhibited a broad spectrum activity on all strains also high antioxidant activity due to the presence of various phytochemicals (Anjaneyalu et al., 2010). The isolated compounds of stem bark of Garcinia malaccensis, $\alpha$ - and $\beta$-mangostin and cycloart-24-en-3 $\beta$-ol showed high cytotoxic, antioxidant and antibacterial activity (Taher et al., 2012). In addition, the aqueous and alcoholic extract of stem bark of Cassia fistula was tested for their antibacterial activity. Alcoholic extract $(7.0$ to $12.0 \mathrm{~mm})$ showed greater inhibition against $S$. aureus compared to aqueous extract (7.0 to $11.6 \mathrm{~mm}$ ) (Vimalraj et al., 2009). The stem bark Manilkara zapota was also evaluated for in vivo antitumor activity against EAC in Swiss albino mice, and the ethyl acetate fraction was said to possess significant antitumor activity (Osman et al., 2011).

Furthermore, the bark extracts of Bauhinia purpurea were phytochemically analyzed and evaluated for antimicrobial and antioxidant activities. Among the different solvent extracts, aqueous and methanolic extract exhibited a broad spectrum of antimicrobial (antibacterial and antifungal) activity and 80 to $90 \%$ antioxidant activity in terms of DPPH radical scavenging activity (Avinash et al., 2011). The antimicrobial and phytotoxic activities of the crude methanolic extract and its subsequent solvent fractions of Pistacia integerrima bark were investigated. The outstanding activity was shown by the ethyl acetate fraction followed by aqueous fraction against $S$. aureus having zone of inhibition of 19 and $15 \mathrm{~mm}$, respectively (Rahman et al., 2011). The antibacterial activity of all extracts from Tectona grandis (Teak) were also checked against important hospital strains by disc diffusion assay, where chloroform extract showed inhibition to growth of $S$. aureus $(14 \mathrm{~mm})$ and $K$. pneumoniae $(8 \mathrm{~mm})$, and also a high cytotoxicity against chick embryo fibroblast (CEF) and human embryonic kidney (HEK 293) cells with 87 and $95.3 \%$ inhibition, respectively (Krishna et al., 2010).

\section{Conclusion}

The present study indicates that the ethanolic bark of $M$. tetracoccus (Roxb.) Kurz. is high in phenolic and flavonoid content. Also, the results of scavenging activities observed against DPPH, reducing power, phosphomolybdenum activities, metal chelating shows that M. tetracoccus (Roxb.) Kurz. provide promising natural sources of antioxidants suitable for preventing free radical-mediated diseases. The extract also showed high antibacterial against important clinical bacterial isolates. Further studies are needed to explore the potential phenolics and flavonoid compounds from $M$. tetracoccus bark for application in drug delivery, nutritional or pharmaceutical fields.

\section{ACKNOWLEDGEMENT}

The author Ramalakshmi $S$ is thankful to UGC for providing meritorious fellowship (UGC-BSR).

\section{REFERENCES}

Al-Naqeeb G, Ismail MS, Al-Zuba A (2009). Fatty acid profile, aTocopherol content and total atioxidant activity of oil extracted from Nigella sativa seeds. Int. J. Pharmacol. 5(4):244-250.

Amakura Y, Yoshida T (1996). Tannins and related polyphenols of euphorbiaceous plants. 14. Euphorbin I, a new dimeric hydrolyzable tannin from Euphorbia watanabei. Chem. Pharm. Bull. 44:1293-1297.

Anjaneyalu E, Ramgopal M, Hemaltha S, Balaji M (2010). Phytochemical analysis, anti microbial and antioxidant activity of the bark extarcts of Acacia leucophloea L. Global J. Biotechnol. Biochem. 5(4):231-236.

Arfan $M$, Amin H, Karamać M, Kosińska A, Amarowicz R, Shahidi $F$ (2007). Antioxidant activity of extracts of Mallotus philipensis fruits and bark. J. Food Lipids 14:280-297.

Avinash P, Idress H. Attitalla M, Ramgopal F, Santhosh C, Balaji M (2011). In vitro antimicrobial and antioxidant activities of bark extracts of Bauhinia purpurea. Afr. J. Biotechnol. 10(45):9160-9164.

Bauer AW, Kirby WMM, Sherris JC, Turck M (1966). Antibiotic susceptibility testing by a standardized single disk method. Am. J. Clin. Pathol. 45:493-496.

Behbahani M, Ali AM, Muse R, Mohd NB (2007). Anti oxidant and antiinflammatory activities of leaves of Barringtonia racemosa. J. Med. Plants Res. 7(1):095-102.

Braca A, Sortino C, Politi M (2002). Antioxidant activity of flavonoids from Licania licaniaeflora. J. Ethnopharmacol. 79:379-381.

Chang CC, Yang MH, Wen HM, Chern JC (2002). Estimation of total flavonoid content in propolis by two complementary colorimetric methods, J. Food Drug Anal. 10:178-182.

Chang ST, Wu JH, Wang SY, Kang PL, Yang NS, Shyur LF (2001). Antioxidant Activity of Extracts from Acacia confusa Bark and Heartwood . J. Agric. Food Chem. 49:3420-3424.

Chattopadhyay D, Arunachalam G, Mandal AB, Sur TK, Mandal SC, Bhattacharya SK (2002). Antimicrobial and anti-inflammatory activity of folklore: Mallotus peltatus leaf extract. J. Ethnopharmacol. 82:229237.

Cheng XF, Chen ZL (1999). Two new diterpenoids from Mallotus apelta Muell. Arg. J. Asian Nat. Prod. Res. 1:319-325.

Cragg GM, Newman DJ (2000). Antineoplastic agents from natural sources: achievements and future directions. Expert Opin. Investig. Drugs 9:1-15.

Dinis TCP, Madeira VMC, Almeida LM (1994). Action of phenolic derivatives (acetoaminophen, salicilate and 5-aminosalicilate) as inhibitors of membrane lipid peroxidation and as peroxyl radical scavengers. Arch. Pharm. Res. 315:161-169.

Ebrahimzadeh MA, Pourmorad F, Bekhradnia AR (2008). Iron chelating activity screening, phenol and flavonoid content of some medicinal plants from Iran. Afr. J. Biotechnol. 7(18):3188-3192.

Gardner PT, White TC, Mcphail DB, Duthie GG (2000). The relative contributions of vitamin $C$, carotenoids and phenolics to the antioxidant potential of fruit juices. Food Chem. 68:471-474.

Halliwell B (1997). Antioxidants and human diseases: a general introduction. Nutr. Rev. 55:S44-S52. 
Halliwell B, Gutteridge JMC (1990). Role of free radicals and catalytic metal ions in human disease: an overview. Methods Enzymol. 186:185.

Huang PL, Wang LW, Lin CN (1999). New triterpenoids of Mallotus repandus. J. Nat. Prod. 62:891-892.

Jensen A (1978). Chlorophyll and carotenoids. In: Hallebust JA, Craigie JS (eds). Handbook of Physiochemical and biochemical Methods. Cambridge University Press, Cambridge, UK. pp. 5-70.

Kessler M, Ubeaud G, Jung L (2003). Anti- and pro-oxidant activity of rutin and quercetin derivatives. J. Pharm. Pharmacol. 55:131-142.

Kikuzaki H, Nakatani N (1993). Antioxidant Effects of Some Ginger Constituents. J. Food Sci. 58(6):1407-1410.

Kim HS, Lim HK, Chung MW, Kim YC (2000). Antihepatotoxic activity of bergenin, the major constituent of Mallotus japonicus, on carbon tetrachloride-intoxicated hepatocytes. J. Ethnopharmacol. 69:79-83.

Krishna MS, Jayakumaran NA (2010). Antibacterial, Cytotoxic and Antioxidant Potential of Different Extracts from Leaf, Bark and Wood of Tectona grandis. I. J. Pharm. Sci. Drug Res. 2(2):155-158.

Lee J, Jiang S, Levine N, Watson R (2000). Carotenoid supplementation reduces erythema in human skin after simulated solar radiation exposure. PSEMB 2231:170-174.

Likhitwitayawuid K, Supudompol B (2005). A new phloroglucinol dimer from Mallotus pallidus. Heterocycles 65:161-164.

Lu Y, Foo Y (2000). Antioxidant and radical scavenging activities of polyphenols from apple pomace. Food Chem. 68:81-85.

Lu F, Foo LY (1995). Phenolic antioxidant component of evening primrose. In Ong ASH, Niki E and Packer L (Eds.). Nutrition, lipids, health and disease. Champaign: American Oil Chemists Society Press.

Ma J, Jones SH, Hecht SM (2004). A coumarin from Mallotus resinosus mediates DNA cleavage. J. Nat. Prod. 67:1614-1616.

Marimuthu P, Wu CL, Chang HT, Chang ST (2008). Antioxidant activity of the ethanolic extract from the bark of Chamaecyparis obtusa var. formosana. J. Sci. Food Agric. 88:1400-1405.

Taher M, Susanti D, Rezali MF, Zohri FSA, Ichwan SJA, Alkhamaiseh SI, Ahmad F (2012). Apoptosis, antimicrobial and antioxidant activities of phytochemicals from Garcinia malaccensis Hk.f. Asian Pac. J. Trop. Med. pp. 136-141.

Nabavi SF, Nabavi SM, Ebrahimzadeh MA, Asgarirad H (2011). The antioxidant activity of wild medlar (Mespilus germanica L.) fruit, stem bark and leaf. Afr. J. Biotechnol. 10(2):283-289.

Osman MA, Rashid MM, Aziz MA, Habib MR, Karim MR (2011). Inhibition of Ehrlich ascites carcinoma by Manilkara zapota L. stem bark in Swiss albino mice. Asian Pac. J. Trop. Med. pp. 448-451.

Ottolenghi A (1959). Interaction of ascorbic acid and mitochondrial lipids. Archiv. Biochem. Biophys. 79:355-358.

Patil SM, Kadam VJ, Ghosh R (2009). In vitro antioxidant activity of methanolic extract of stem bark of Gmelina arborea roxb. (verbenaceae). J. Pharm. Tech. Res. 1(4):1480-1484.

Prieto P, Pineda M, Aguilar M (1999). Spectrophotometric quantitative of antioxidant capacity through the formation of a phosphomolybednum complex: specific application to the determination of vitamin E. Anal. Biochem. 269:337-341.

Rahman SU, Ismail M, Muhammad N, Ali F, Chishti KA, Imran M (2011). Evaluation of the stem bark of Pistacia integerrima Stew ex Brandis for its antimicrobial and phytotoxic activities. Afr. J. Pharm. Pharmacol. 5(8):1170-1174.
Rahmat A, Kumar V, Fong LM, Endrini S, Sani HA (2003). Determination of total antioxidant activity in three types of local vegetables shoots and the cytotoxic effect of their ethanolic extracts against different cancer cell lines. Asia Pac. J. Clin. Nutr. 12(3):292295.

Ramalakshmi S, Muthuchelian K (2011). Anlaysis of bio-active constituents from the leaves of Mallotus tetracoccus (Roxb.) Kurz by Gas Chromatography-Mass Spectrometry. I J. Pharm. Sci. Res. 2(6):1449-1454.

Saha K, Lajis NH, Israf DA, Hamzah AS, Khozirah S, Khamis S, Syahida A (2004). Evaluation of antioxidant and nitric oxide inhibitory activities of selected Malaysian medicinal plants. J. Ethnopharmacol. 92(2-3):263-267.

Siddhuraju R, Becker K (2003). Antioxidant properties of various solvent extracts of total phenolic constituents from three different agroclimatic origins of drumstick tree (Moringa loifera Lam.) leaves. J. Agric. Food Chem. 51:2144-2155.

Siddhuraju P, Mohan PS, Beaker K (2002). Studies on the antioxidant activity of Indian Laburnum (Cassia fistula L.) A preliminary assessment of crude extracts from stem, bark, leaves and fruit pulp. Food Chem. 79:61-67.

Sowndhararajan K, Joseph JM, Rajendrakumaran D, Manian S (2010). In vitro antioxidant characteristics of different parts of Melothria maderaspatana (L.) COGN. Int. J. Pharm. Pharm. Sci. 2(3):117-123.

Tanaka T, Ito T, linuma M, Takahashi Y, Naganawa H (1998). Dimeric chalcone derivatives from Mallotus philippensis. Phytochemistry 48:142-1427.

Vimalraj TR, Saravana kumar S, Vadivel S, Ramesh S, Thejomoorthy P (2009). Antibacterial effect of Cassia fistula extract on pathogenic bacteria of veterinary importance. Tamilnadu J. Vet. Anim. Sci. 5(3):109-113.

Viswanatha GLS, Vaidya SK, Ramesh C, Nandakumar K, Rangappa S (2010). Antioxidant and antimutagenic activities of bark extract of Terminalia arjuna. Asian Pac. J Trop. Med. 3(12):965-970.

Wei K, Li W, Koike K, Liu LJ, Fu XW, Lin LB, Chen YJ, Nikaido T (2004). Two new galloylglucosides from the leaves of Mallotus furetianus. Chem. Pharm. Bull. 52:776-779.

www.biotik.org

Yamaguchi T, Takamura H, Matoba T, Terao J (2002). HPLC method for evaluation of the free radical scavenging activity of foods by using 2, 2-diphenyl-1-picryl hydrazyl. Biol. Sci. Biotechnol. Biol. Chem. 62:1201-1204. 